\title{
Securities market theory: possession, repo and rehypothecation
}

\author{
Jean-Marc Bottazzi $^{a} \quad$ Jaime Luque $^{b} \quad$ Mário R. Páscoa $^{c}$
}

\footnotetext{
* The authors thank the comments of John Geanakoplos, Piero Gottardi and Herakles Polemarchakis, and two anonymous referees. Jaime Luque and Mário Páscoa gratefully acknowledge support from FCT and FEDER through project PTDC/ECO/64968/2006. Jaime Luque gratefully acknowledges the Spanish Ministry of Education and Science for financial support under grant SEJ2008-03516. This research was initiated while J-M. Bottazzi was working at J.P. Morgan. ${ }^{a}$ Capula and Paris School of Economics (CES), FRANCE. e-mail: jeanmarc@bottazzi.org ${ }^{b}$ Departamento de Economía, Universidad Carlos III de Madrid, SPAIN; e-mail: japluque@eco.uc3m.es ${ }^{c}$ CORRESPONDING AUTHOR'S ADDRESS: Mário Páscoa, Faculdade de Economia, Universidade Nova de Lisboa, Campus de Campolide; 1099-032 Lisboa, PORTUGAL. e-mail: pascoa@fe.unl.pt
} 


\begin{abstract}
By introducing repo markets we understand how agents need to borrow issued securities before shorting them: (re)-hypothecation is at the heart of shorting. Non-negative amounts of securities in the box of an agent (amounts borrowed or owned but not lent on) can be sold, and recursive use of securities as collateral allows agents to leverage their positions. A binding box constraint induces a liquidity premium: the repo rate becomes special and the security price higher than expected discounted cash-flows. Existence of equilibrium is guaranteed under limited re-hypothecation, a situation secured by (current or proposed) institutional arrangements.
\end{abstract}

JEL classification numbers: D52, D53, G12.

Keywords and Phrases. re-hypothecation, repo, leverage, repo collateral multiplier, short sale, issuing, collateral, specialness, security pricing. 


\section{Introduction}

\subsection{Motivation}

Never as acutely before, has repo's role in the provision of liquidity attracted as much attention from policy-markers, as in the context of the recent credit crisis. ${ }^{1}$ Yet repo and term repos have always been widely used by the central bankers. The credit protection of the collateral made repo a tool of choice in the execution of open market operations to adjust money supply, mostly through government bonds repos. In particular, repo is routinely used to drain funds. ${ }^{2}$

It is now more evident, after the recent crisis, how intricate funding, leverage and pricing are. Policy makers tried to manage the leverage cycle by intervening in repo markets, providing selective funding to prevent disorderly de-leveraging. The repo market is where the short term scarcity of securities is priced. In the recent crisis it became quite clear that the ability of large holders of securities to fund their positions can have as much impact on security prices as the fundamental value of the securities. Without taking into account repo markets, one fails to model several important aspects of the security market, namely the difference between shorting and issuing a security, how leverage can be build up and securities can have a liquidity premium due to their use as collateral in repo.

\section{$1.2 \quad$ Hypothecation theory}

So far, security market models have not distinguished properly shorting from issuing. Whereas some models allowed for an initial supply of securities, it was not clear how one could sell what one was not endowed with. The distinction is important because the right to issue is granted to a few people only: for shares it is linked to control of a firm, for issuance of debt this can only be done by the executive of a firm or a government in accordance with owners (or voters), as it potentially exposes the entire debt issuing entity to bankruptcy. On the other

\footnotetext{
${ }^{1}$ Funding and repos have been one of the main tools to normalize market conditions as funding becomes difficult. An example is the Term Auction Facility (TAF) program introduced by the Federal Reserve (official release: http://www.federalreserve.gov/newsevents/press/monetary/20071212a.htm).

${ }^{2}$ Usually, in these repo operations, no specific bond categories are targeted, with the exception of the innovative repo operations on specials by the Bank of England (see www.jdawiseman.com/papers/finmkts/opnot1609.pdf).
} 
hand, shorting is the activity of selling a security one just borrowed (but did not originally own). Agents' inability to issue should have a price impact, like most constraints or frictions. In the present paper we set up an institutional framework that clearly distinguishes shorting (by those that borrowed the security) and issuance (through initial endowments of the security). We focus here on shorting and for all purposes, we look at the situation after all issuance is finished.

The above distinction is the foundation for (re)-hypothecation. Once a market for lending securities is introduced, it would be impractical to require to find out if the agent in possession of the security is its original owner. In fact, rather than trying to find that out (like in the real-estate pre-transaction validation to know if a sale is legitimate), the securities market rules deal with the situation quite elegantly: it does not matter. The immediate rights of the agent in possession of the security title are the same as the ones of a full owner. ${ }^{3}$ Any possessing agent can legitimately sell such a security or lend it further. This is what is called rehypothecation of the security and is at the core of securities market mechanisms. We use the term with a broad meaning ${ }^{4}$. Fungibility of securities means that not the same security with exact serial numbers should be returned to the lenders - like with cash (and bank notes) different equivalent titles of the security are perfectly acceptable!

Possession demand has striking implications for security pricing and repo specialness. Standard non-arbitrage theory values assets by discounting expected cash-flows for some pricing probability. We find that this is not always valid for securities: there is a rent associated to being in possession of the physical security. In particular, the scarcity of the security affects both pricing of the security and of the repo rate. The scarcer the security, the lower the repo rate associated with borrowing the security, and the higher the value of the security. This may remind us of results where prices are impacted by frictions introduced in the model, but here no friction is introduced and rent can occur in normal conditions of a frictionless securities market: its source is the mere scarcity of the security and its possession demand. ${ }^{5}$ This fundamental difference limits the

\footnotetext{
${ }^{3}$ There are collateralized funding markets in the securities world that do not obey this: the asset is pledged but the title not transferred. The asset back commercial paper (ABCP) market is an example.

${ }^{4}$ When there is a central security registry, we think of a change of name associated to the title. With bearer's security we think of the concrete equivalent: physical possession of the title is passed on.

${ }^{5}$ In Araujo, Fajardo and Páscoa [3] binding collateral constraints introduced an analogous
} 
applicability of derivative pricing to securities used as collateral.

Another feature of our repo model is that re-hypothecation allows agents to recursively leverage their positions. Agents who borrow securities use the short sales revenue to give new cash loans in exchange for new security borrowing and agents who lend securities use cash loans to purchase securities and lend them further.

\subsection{Relationship with the literature}

While important work has been done on the equilibrium modeling of repos (in the pioneering article by Duffie [10], in Duffie et al. [11] and, more recently, in Vayanos and Weill [26] and Brunnermeier and Pedersen [7]), one senses that a broad general equilibrium framework that brings repo and preferences together is needed in order to understand domino effects in a leveraged economy. Without it, the understanding of the welfare implications of policies that attempt to impact leverage and funding would be quite limited. Trying to take this seriously, we build a basic general equilibrium model of repo and securities markets.

Equilibrium analysis is particularly important in a repo context since, as Duffie [10] remarks, it is possible to bound repo rates from above by arbitrage, but there is no arbitrage argument to find a lower bound and these rates may become negative. The level of such rates comes out of the equilibrium (as a price).

One should think of a repo rate as a market clearing price, influenced by funding needs, and the rent associated with holding a specific security. Securities in relative scarcity trade on special (i.e. below the General Collateral rate (GC), which is the highest repo rate for a given term and securities issuer $)^{6}$. Duffie's [10] leading paper on repo markets, first introduced repo specialness in the field of study. Subsequent empirical work was done by Jordan and Jordan [22]. Duffie et al. [11] modeled search in the repo market and showed that it generates a positive lending fee. Vayanos and Weill [26] built a search model and explained price differentials among otherwise identical assets. We link specialness to the shadow

effect on the price of mortgages and of the durable good used as collteral. In Fostel and Geanakoplos [13], assets serve as collateral for money promises and, when collateral constraints are binding, asset prices include the respective shadow values.

${ }^{6}$ In the case of Treasuries and next-day repurchases, the upper bound is at or near to the overnight interest rate in the market for Federal funds. 
price of a new constraint, called the box constraint, that requires the possession balance/title ownership in each security (the amount that is purchased, endowed with or borrowed, net of what is lent or short sold) to be non-negative. Naked security positions are not allowed ${ }^{7}$ and the portfolio space is no longer a linear space.

How does our paper relate to previous work on collateral? In the pioneering model by Geanakoplos and Zame [17] financial assets are backed by a durable good. ${ }^{8}$ As such this collateral enters directly into the agents' utility functions. Financial assets are non-recourse loans (default penalties may be incorporated in the payoff functions as a consequence). The authors have in mind a situation where the house is the collateral for a mortgage and agents are households. In contrast, we look at how securities themselves naturally serve as collateral in the repo market. The collateral premium for durable goods in Geanakoplos and Zame [17] is replaced by a liquidity premium in security prices associated with the possession (non-negativity) multipliers of the box constraint we introduced (securities possession is non-negative and thus bounded below, like a consumption). Essentially, we are interested in the wholesale securities market in its normal operation, and the role of repo market in leverage. Let us be more precise.

Shorting and issuing of securities were formally identical in the traditional Radner-like setting (including works cited here). The quantity of housing bought caps the amount of securities (mortgage) that could be issued in Geanakoplos and Zame [17]. The finite supply of housing thus yields short sales constraints in [17]. In the repo market, however, the pledged collateral is fully recycled: it can be re-lent and sold by the counter-party it is lent to. This re-hypothecation, more than the nature of the collateral, constitutes the deep difference with the cited work. With securities, possession alone is as good as original ownership.

Re-hypothecation means a new kind of "pyramiding", with securities positions secured by securities as collateral in Geanakoplos's [15] terminology. Very dif-

\footnotetext{
${ }^{7}$ Our paper is about shorting securities (stocks and bonds), which implies physical delivery. We do not attempt to model other types of shorting, in particular, derivatives (e.g. interest rate swaps, futures, options), but notice that, in this case, "shorting" means the instrument is closely related to a security or a good in positive supply. OTC dealers will typically hedge such an instrument in the securities market. For exchange traded futures, possession of goods and securities will be the driver of the delivery process. Repo markets are very relevant in most cases.

${ }^{8}$ Among many of subsequent related papers see Araujo, Pascoa and Torres-Martínez [2], Geanakoplos [14] and Fostel and Geanakoplos [13].
} 
ferent from the financial engineering of Collateral Bond Obligations (CBO) and various variations such as CLOs, CDOs etc... (see Geanakoplos and Zame [17]), our pyramiding occurs in the regular day to day business of trading securities. It is not a pyramiding of credit, it affects the very ability to take and hold a position. Collateral used in repo are securities themselves (and do not enter in the preferences). Our approach applies to active traders of the securities market (banks, government agencies, insurance companies, hedge funds etc...) with their respective trading strategies. In this paper we do not introduce default (failure to return money) and fails (failure to return a security) yet. The natural extensions of our model will distinguish and accommodate those.

In short, while previous general equilibrium work we cite focused on building a theory of asset backed securities, we model how securities serve as collateral in repo markets and the importance of re-hypothecation.

\subsection{Structure}

The rest of this paper is as follows. Section 2 introduces the repo market and shows how repo and securities markets interact in the leverage process. We call this expansion of position beyond physical securities available "the repo collateral multiplier". In Section 3 we see how to tweak the standard equilibrium concept to accommodate for re-hypothecation and repo markets. In section 4 , we show that in a context of limited re-hypothecation an equilibrium exists. We go over some important institutional impediments that implement limited re-hypothecation: (1) segregated accounts and (2) constrained dealers.

With one security the presence of a haircut, naturally bounds budget sets. This does not directly extend to more than one security as agents can combine being posted haircuts with posting haircuts. Our approach to analyze the problem is to prevent agents to use haircuts (paid for with counter-parties own money) for their own purposes. This bounds re-hypothecation rates. Another approach is to introduce more realistic specifications with two types of agents: dealers who can receive haircut but have a bound "a la Radner", derived from the many regulations bounding the balance-sheet of dealers, and their customers who post and never receive haircut, and can only do repos with dealers. 


\section{Repo and leverage}

Let us start by introducing the repo market. A repo trade consists in a security sale combined with an agreement of future repurchase of the same amount at a predetermined date and price. Securities are valuables ${ }^{9}$, and as such they are an appropriate collateral to pledge against a loan. This is what a repo trade is. Thus in a repo trade there are two parties involved: the lender and the borrower of the security. Cash-flows (e.g., coupon or dividend) received from the securities during the repo trade are passed on to the original owner (engineered). ${ }^{10}$ What distinguishes repo trades from simple sales and purchases of securities is how the front leg and the back leg of the trade are linked as one trade. The difference between the sale price and the future repurchase price corresponds to a level of interest rate which is called the repo rate. The repo trade is a collateralized loan of cash at the repo rate. The duration of the repo transaction is shorter than the time to maturity of the security. The repo rate is a market level. Higher interest rates are an upward pressure on the repo rate. On the other hand, the value associated to desirability of being in possession of the security and to the credit protection brought by the collateral both push the repo rate down.

Positions taken in the securities market and the repo market are typically, but not always, in opposite directions. Agents who borrow the security (possibly in order to short sell it) are long in repo, whereas those lending the security (to obtain funding to purchase it) are short in repo. The language used for repo may seem tricky at first. The terminology becomes very natural provided one focuses on the effect of trades on title balance of given security, called the amount in the box in market parlance. In the case of bearer securities for which the title is represented by a physical piece of paper, the box can be literally thought as a box or vault where one puts such titles. In fact, such record and safe-keeping is most often done electronically and delegated to a custodian. The humble original bearer form of securities, nevertheless, left its institutional mark on how the securities markets operate. ${ }^{11}$ Getting long a security in the securities or in

\footnotetext{
${ }^{9}$ For us this will be following from assumption (A2) below. A security is a financial contract whose price is expected to stay positive, something conveyed by the word "security". The definition is related to the Japanese word for security that actually means "valuable certificate".

${ }^{10}$ Such proceeds are not passed on in the case of Buy/Sells and Sell/Buys, and this is the main difference to distinguish Repo and Reverse Repo from the corresponding Sell/Buy (corresponding to Repo) and Buy/Sells (corresponding to Reverse Repo).

${ }^{11}$ While securities (and property) market have moved away from bearer form of the title
} 
the repo markets both increase the amount of the security in the box. A security that one lends disappears from one's box, like a book that one lends disappears from one's shelves. The quantity of title in the box, the securities possessions are non-negative. This non negativity constraint is the inequality introduced by hypothecation in the securities market.

In the rest of this section we show how a leveraged security position is built up by the succession of trades in the securities and repo markets. We analyze how the entanglement of funding and trading can give rise to a collateral multiplier, where the initial supply of securities is expanded into larger positions across the economy in a process similar to the one at work with the money multiplier.

Let there be two agents, Ms. A and Mr. B, with initial positions

\begin{tabular}{|c|c|c|c|c|}
\hline Moment 0 & Cash Deposit & Repo Position & Security Position & Box Position \\
\hline Ms. A & $c$ & 0 & 0 & 0 \\
\hline Mr. B & 0 & 0 & $C$ & $C$ \\
\hline
\end{tabular}

where the value of the amount of the security held by $\mathrm{Mr}$. B, $q C$, equals to the cash held by Ms. A, c. Now let Ms. A buy the security from Mr. B with her cash. Note that Mr. B can sell the security to Ms. A because he already has it (i.e. it is in his box). The positions become

\begin{tabular}{|c|c|c|c|c|}
\hline Step 1, Moment 1 & Cash Deposit & Repo Pos. & Security Pos. & Box Pos. \\
\hline Ms. A & 0 & 0 & $C$ & $C$ \\
\hline Mr. B & $c$ & 0 & 0 & 0 \\
\hline
\end{tabular}

Next, Ms. A, who has the balance $C$ in her box, lends $C$ of the security to Mr. B and uses this to collateralize a loan (repo), so Ms. A can borrow the haircutted amount $h c$ in cash (where $1-h$ denotes the haircut, $h \in[0,1)$ in this example). Thus

\begin{tabular}{|c|c|c|c|c|}
\hline Step 1, Moment 2 & Cash Deposit & Repo Pos. & Security Pos. & Box Pos. \\
\hline Ms. A & $h c$ & $-C$ & $C$ & 0 \\
\hline Mr. B & $(1-h) c$ & $C$ & 0 & $C$ \\
\hline
\end{tabular}

(toward a central register in most cases), the institutional mechanisms (and representations) has been mostly determined by this bearer form of the security. 
In the previous transactions Ms. A is long in the security (moment 1) and short in repo (moment 2), and the opposite for Mr. B. Since the cash received from the borrowed security is passed on from Mr. B to Ms. A, it looks like Ms. $\mathrm{A}$ is borrowing money for the term of the repo to buy the security. She receives cash-flows occurring during the repo transaction.

Step 2 starts and agents replicate Step 1. This is moment 3. Now Ms. A can use her cash deposit to buy the security she just lent before, which left her box empty. Mr. B sells $h C$, a portion of the security $C$ he received as collateral from Ms. A in moment 2. Mr. B is entitled to sell this because he has it in his box. Observe that at moment 3 Ms. A cannot afford a larger purchase of the security because of Mr. B's moment 2 haircut. The positions become

\begin{tabular}{|c|c|c|c|c|}
\hline Step 2, Moment 3 & Cash Deposit & Repo Pos. & Security Pos. & Box Pos. \\
\hline Ms. A & 0 & $-C$ & $(1+h) C$ & $h C$ \\
\hline Mr. B & $c$ & $C$ & $-h C$ & $(1-h) C$ \\
\hline
\end{tabular}

At this point $h C$ of the security is in Ms. A's box. Ms. A posts her collateral in a repo with Mr. B and borrows a further $h^{2} c$ amount of cash. We have

\begin{tabular}{|c|c|c|c|c|}
\hline Step 2, Moment 4 & Cash Deposit & Repo Pos. & Security Pos. & Box Pos. \\
\hline Ms. A & $h^{2} c$ & $-(1+h) C$ & $(1+h) C$ & 0 \\
\hline Mr. B & $\left(1-h^{2}\right) c$ & $(1+h) C$ & $-h C$ & $C$ \\
\hline
\end{tabular}

Repeating all the steps, after the $n^{\text {th }}$ iteration, we get

\begin{tabular}{|l|c|c|c|c|}
\hline Step $n$ & Cash & Repo Pos. & Security Pos. & Box Pos. \\
\hline Ms. A & 0 & $-\left(1+h+\ldots+h^{n-1}\right) C$ & $\left(1+h+\ldots+h^{n}\right) C$ & $h^{n} C$ \\
\hline Mr. B & $c$ & $\left(1+h+\ldots+h^{n-1}\right) C$ & $-\left(h+\ldots+h^{n}\right) C$ & $\left(1-h^{n}\right) C$ \\
\hline
\end{tabular}

The positions in the limit are

\begin{tabular}{|c|c|c|c|c|}
\hline Step $\infty$ & Cash & Repo Pos. & Security Pos. & Box Pos. \\
\hline Ms. A & 0 & $-\frac{C}{1-h}$ & $\frac{C}{1-h}$ & 0 \\
\hline Mr. B & $c$ & $\frac{C}{1-h}$ & $-\frac{h C}{1-h}$ & $C$ \\
\hline
\end{tabular}


Observe that in the limit the amount of the security in Ms. A and Mr. B's box are 0 and $C$, respectively, which coincide with the initial positions in moment 0 . However, net Ms. A has managed to leverage her cash $\frac{1}{1-h}$ times to build a security long position. For example, for a haircut of $2 \%$ the leverage would be of 50 to 1 . The repo collateral multiplier tells us that the repo transactions can be looped without any uncertainty being resolved. ${ }^{12}$

\section{A GE model of repo}

\subsection{Fundamentals}

We will now formally introduce the repo market in the standard GEI model and see the implications for securities pricing theory. The economy is represented by three dates, $t \in\{0,1,2\}$. Agents can trade commodities and securities at date 0 . At date 1 agents trade securities and commodities and repos must be settled. The set of states of nature at date 1 is $\mathbf{S}=\{1, \ldots, s, \ldots, S\}$. The last date just serves for guaranteeing that securities retain a value at date 1 when repos are settled, and therefore, to simplify, we assume that no uncertainty is to be resolved between dates 1 and 2 (that is, each node $s$ at date 1 has just one successor $s^{+}$. The set of states at date 2 is denoted by $\mathbf{S}^{+}=\left\{1^{+}, \ldots, s^{+}, \ldots, S^{+}\right\}$. More generally, a date-state node $\xi$ is a point of the history tree: $\xi \in \Sigma \equiv\left\{0,1, \ldots, S, 1^{+}, \ldots, S^{+}\right\}$.

The set $\mathbf{J}=\{1, \ldots, j, \ldots, J\}$ represents the securities available in the economy. Securities live up to date 2. The set of commodities is $\mathbf{L}=\{1, \ldots, l, \ldots, L\}$. There is a finite set $\mathbf{I}=\{1, \ldots, i, \ldots, I\}$ of individuals (or agents). We denote by $x_{\xi}^{i} \in \mathbb{R}_{+}^{L}$ the consumption vector of commodities at date-state $\xi \in \Sigma$. A consumer obtains utility from his consumption $x^{i}=\left(x_{\xi}^{i}\right)_{\xi \in \boldsymbol{\Sigma}} \in \mathbb{R}_{+}^{(1+2 S) L}$. Consumers' utility functions $u^{i}$ have an effective domain contained in $\mathbb{R}^{(1+2 S) L}$. Next, we impose an assumption on endowments and utilities (smooth preferences, Debreu [8]):

(A1) For every $i \in \mathbf{I}$, we assume that (i) individual endowment of commodities is $\omega_{\xi}^{i} \gg 0, \forall i, \xi$ and the total initial security endowments are $e_{0}^{i} \gg 0, \forall i{ }^{13}$ (ii) the

\footnotetext{
${ }^{12}$ Observe that in the present framework we are considering the ideal scenario of immediate settlement for repo and security markets. Most arguments can be generalized by matching settlement instructions ahead of payment.

${ }^{13}$ Issuance has already happened, and issued securities have been placed. Agent thus have initial endowments of securities describing their holdings when trading starts.
} 
utility function $u^{i}$ is twice continuously differentiable, (iii) $D u^{i}(x) \in \mathbb{R}_{++}^{(1+2 S) L}$, $\forall x \in \mathbb{R}_{+}^{(1+2 S) L}$, (iv) $\forall c \in \mathbb{R}$, the set $\left[u^{i}\right]^{-1}(c)$ is closed in $\mathbb{R}_{++}^{(1+2 S) L}$, and (v) at every $x \in \mathbb{R}_{++}^{(1+2 S) L}, h^{\prime} D^{2} u^{i}(x) h<0, \forall h \neq 0$ such that $D u^{i}(x) h=0 .^{14}$

It is well known that under assumptions (A1)(ii)-(v) the utility function is quasi-concave and such that $u^{i}(\alpha x+(1-\alpha) z)>\min \left\{u^{i}(x), u^{i}(z)\right\}$ when $u^{i}(x) \neq$ $u^{i}(z), \alpha \in(0,1)$. Assumptions (A1)(ii)-(v) will allow us to bound intertemporal marginal rates of substitution, from above and from below (and find positive lower bounds for security prices). We want to emphasize that, for this purpose, concavity of utilities could have been assumed instead.

Security trading occurs at dates 0 and 1 . Denote by $y_{j \xi}^{i}$ the trade in security $j$ at node $\xi=\left\{0,(s)_{s \in \mathbf{S}}\right\}$. The position of agent $i$ in security $j$ at node $\xi$ is $\phi_{j \xi}^{i}$. For $\xi=0$, the position is $\phi_{j 0}^{i}=e_{j 0}^{i}+y_{j 0}^{i}$. Let us denote by $\xi_{-}$the predecessor node of $\xi$. Then, for node $\xi>0$, the current position is $\phi_{j \xi}^{i}=\phi_{j \xi_{-}}^{i}+y_{j \xi}^{i}$ (the previous position plus current trade). Hence, a short sale happens when $\phi_{j \xi}^{i}<0$ (the position gets negative). The security market transactions of node $\xi$ take place at a price denoted by $q_{j \xi}$.

Securities are real ${ }^{15}$. The real proceeds of security $j$ at date-state $\xi>0$ are exogenously given by a non-zero vector $B_{j \xi} \in \mathbb{R}_{+}^{L}$. We assume that

(A2) For any state $s \in \mathbf{S}$, the real returns matrix $B_{s}$ of type $L \times J$ does not have null rows (that is, each good has at least some security paying in that $\left.\operatorname{good}^{16}\right)$.

In this case, securities are valuables since they can be thought as having the value of a commodity basket. Given spot prices $p_{\xi} \in \mathbb{R}_{+}^{L}$, the nominal return of security $j$ is $p_{\xi} B_{j \xi}$. Taking into account security proceeds, we have that the total endowments of physical commodities at state $s$ of date 1 are $\sum_{i} \tilde{\omega}_{s}^{i}=\sum_{i} \omega_{s}^{i}+$ $\sum_{j} B_{j s} \sum_{i}\left(y_{j 0}^{i}+e_{j 0}^{i}\right)$. Similarly, the total endowments of physical commodities at date 2 and state $s^{+}$are $\sum_{i} \tilde{\omega}_{s^{+}}^{i}=\sum_{i} \omega_{s^{+}}^{i}+\sum_{j \in \mathbf{J}} B_{j s^{+}} \sum_{i}\left(y_{j s}^{i}+y_{j 0}^{i}+e_{j 0}^{i}\right)$.

We will depart from the standard budget constraint of the standard GEI model (where shorting is done without any reference to repo).

\footnotetext{
${ }^{14}$ Here $D$ denotes the differentiation operator.

${ }^{15}$ i.e. securities pay in commodities or a numeraire. We could have modelled securities that pay instead in units of account but chose to focus on the case of real securities to highlight the relevance of repo markets to the well-known problem of existence of equilibrium with real assets. See Luque [24] on the nominal securities case.

${ }^{16}$ For example, if there is a forward term contract for each good.
} 


\subsection{Hypothecation theory}

Somebody who wants to short a security will contact a holder of that security and ask her "Will you lend me your security?" If the potential lender says yes, she takes money from the borrower of security and lends the security. She agrees with the borrower that he will give back the same quantity of the fungible security at a later date. Now if the borrower of the security takes the title to the market there is no direct way to know if he is the original owner of the security. In fact, after borrowing the title it is legitimate to sell the security, or to lend it further. This transfer of possession is called re-hypothecation and is a core feature of securities markets. Note that from the point of view of the lender she may have used the repo transaction to finance the purchase of security.

To make things simple, we focus on anonymous repos, where all traders go to a common repo pool. One should notice that the objective of this paper is on re-hypothecation. No other ingredients such as fails, default and the credit associated to counterparties are considered here. Given this, a model of bilateral repos would complicate things without any further economic insight.

We introduce repo trading by using the variable $z$. Repos are traded at date 0 . The loan associated with repo is $\pi_{j} z_{j}$, where $z_{j}$ represents the amount of security $j$ engaged in the repo and $\pi_{j}=h_{j} q_{j 0}$ is the haircutted price of the collateralized loan, with the haircut $\left(1-h_{j}\right)$ exogenously given. The haircut is imposed to compensate the lender of funds with the risk associated with a simultaneous default and adverse market move of the security lent. ${ }^{17}$ For the sake of simplicity and following typical market practice, we assume that all repos on the same security share a common haircut. ${ }^{18}$ The interest rate on this loan is called the repo rate, denoted by $\rho_{j}$. To simplify the notation we let $r_{j}=1+\rho_{j}$.

\footnotetext{
${ }^{17}$ Typical haircut in normal times are around $1 \%$ or $2 \%$. We will see how the haircut can be a factor bounding the re-hypo rate as we show in our one security leverage example. Apart from that implication for leverage, what we say is valid with no haircut however (simply put $h_{j}=1$ in that case). For endogenous haircuts in the case of mortgages see Geanakoplos [14] and Araujo, Fajardo and Pascoa [3]. In Fostel and Geanakoplos [13] the margins on financial assets collateralizing money promises are also endogenous. In a recent paper, Brunnermeier and Pedersen [7] address the dependence of margins or haicuts on asset's market liquidity.

${ }^{18}$ This can and should be relaxed when we focus more on credit of the trading entities something we do not go into here.
} 
The budget constraint at date 0 becomes $^{19}$ :

$$
p_{0}\left(x_{0}^{i}-\omega_{0}^{i}\right)+q_{0} y_{0}^{i}+\pi z^{i} \leq 0
$$

where $\pi z^{i}=\sum_{j} \pi_{j} z_{j}^{i}$. The budget constraint at state $s$ of date 1 is the following ${ }^{20}$ :

$$
p_{s}\left(x_{s}^{i}-\omega_{s}^{i}\right)+q_{s} y_{s}^{i} \leq p_{s} B_{s}\left(y_{0}^{i}+e_{0}^{i}\right)+r \pi z^{i}
$$

where $r \pi z^{i}=\sum_{j} r_{j} \pi_{j} z_{j}^{i}$. The last date budget constraint takes the form

$$
\left.p_{s^{+}}\left(x_{s^{+}}^{i}-\omega_{s^{+}}^{i}\right) \leq p_{s^{+}} B_{s^{+}}\left(y_{s}^{i}+y_{0}^{i}+e_{0}^{i}\right) \quad \text { (BC.Hyp. } s^{+}\right)
$$

It looks like we added a few debt instruments to the standard GEI model. But if we introduce the non-negativity condition of the box things change. The box constraint dictates that Mr. $i$ 's box contains non-negative balances of securities title of ownership, when repo and security positions are added (i.e., when to quantities purchased or borrowed we subtract quantities sold or lent):

$$
y_{j 0}^{i}+e_{j 0}^{i}+z_{j}^{i} \geq 0, \forall j \in \mathbf{J}
$$

Observe that at date 1 no repo transactions are made, so the corresponding box constraint at state $s$ is a plain no-short sales constraint, ${ }^{21}$ i.e.,

$$
y_{j s}^{i}+y_{j 0}^{i}+e_{j 0}^{i} \geq 0, \forall j \in \mathbf{J}
$$

We now show that the box constraint (Box.0) can be decomposed in the following two constraints:

$$
y_{j 0}^{i}+e_{j 0}^{i}<0 \Longrightarrow z_{j}^{i} \geq-\left(y_{j 0}^{i}+e_{j 0}^{i}\right)
$$

that applies to the agent willing to get short (sell more of the security than he is endowed with): he has to get the balance by borrowing; and

$$
z_{j}^{i}<0 \Longrightarrow y_{j 0}^{i}+e_{j 0}^{i} \geq-z_{j}^{i}
$$

limiting lending agents not to lend more securities than available through initial endowment and trading.

\footnotetext{
${ }^{19}$ whereas this constraint was just $p_{0}\left(x_{0}^{i}-\omega_{0}^{i}\right)+q y_{0}^{i} \leq 0$ in the standard GEI model.

${ }^{20}$ which was $p_{s}\left(x_{s}^{i}-\omega_{s}^{i}\right)+q_{s} y_{s}^{i} \leq p_{s} B_{s}\left(y_{0}^{i}+e_{0}^{i}\right)$ in the GEI model

${ }^{21}$ For simplification, we present an economy where repo markets only open in the initial date, and therefore short sales are only allowed at that initial date. However, in a multiperiod model where repo markets also open after the initial date, we should introduce a box constraint similar to (Box.0) in those other dates.
} 
Observe the interesting interaction between constraints (BC.Hyp.0) and (L). A repo purchase $z_{j}^{i}>0$ involves a repo purchasing cost $\pi_{j} z_{j}$ for awarding the loans; this cost can possibly be recouped by the proceeds from the (short) sale of securities at the market price $q_{j 0}$. In fact, the net of the two will increase the cash balance of the agent by the value of the haircut.

Remark 1: The (Box.0) constraint is equivalent to (L) and $(S) .{ }^{22}$

Duffie [10] already had constraints (L) and (S), but the former was written in equality form. Actually, the inequality form is as acceptable in the former as in the latter. Under the equality form the constraint set was not convex but it is now. Combining (L) and (S), in inequality form, we get the box constraint. ${ }^{23}$

\subsubsection{Security pricing: the box}

The lower bound (zero) on security possessions generates a shadow value that should be taken into account in the valuation of securities (securities do not enter preferences, but the desire to relax this lower bound makes somehow securities good-like).

Let $\lambda_{\xi}^{i}$ stand for agent $i$ 's Lagrange multiplier associated to his budget constraint at each node $\xi$ and let $\mu_{j \xi}^{i}$ be the multiplier of security $j$ box constraint at a node $\xi \in\left\{0,(s)_{s \in \mathbf{S}}\right\}$. The derivative with respect to consumption $x_{\xi}$ yields

$$
D_{x_{\xi}} u(x)=\lambda_{\xi}^{i} p_{\xi} \quad\left(x_{\xi} \text {.Hyp.FOC }\right)
$$

while if taking the derivative with respect to asset trading $y_{j 0}$ one gets

$$
q_{j 0}=\sum_{\xi>0} \frac{\lambda_{\xi}^{i}}{\lambda_{0}^{i}} p_{\xi} B_{j \xi}+\frac{\mu_{j 0}^{i}}{\lambda_{0}^{i}}+\sum_{\xi>0} \frac{\mu_{j \xi}^{i}}{\lambda_{0}^{i}} \quad \text { (y0.Hyp.FOC) }
$$

In our pricing formula some non cash-flow terms are added: $\left(\mu_{j 0}^{i}+\sum_{\xi>0} \mu_{j \xi}^{i}\right) / \lambda_{0}^{i}$. These terms were absent in the standard GEI model, where pricing was done by merely discounting cash-flows. While pricing by discounted expected cash-flows

\footnotetext{
${ }^{22}$ See Luque [24] for a detailed proof.

${ }^{23}$ The inequalities on the thesis side of $(\mathrm{L})$ and $(\mathrm{S})$ may remind us of the collateral constraints in Geanakoplos and Zame [17]. The latter is in fact a collateral constraint for the cash loan done through repo. The analogy in the former is not so close but the short sale of a security requires borrowing it first and formally in $(\mathrm{L}) z_{j}^{i}$ plays the role of the collateral but in fact this short sale is not collateralized.
} 
has been the cornerstone of derivatives pricing theory, one sees that additional collateral value needs to be added for securities. ${ }^{24}$

The first extra term $\mu_{j 0}^{i} / \lambda_{0}^{i}$ stands for the possession value over the period 0 to 1 , while $\left(\sum_{\xi>0} \mu_{j \xi}^{i}\right) / \lambda_{0}^{i}$ is the possession value over period 1 to 2 . This means that some value associated to the scarcity of the security - seen as how binding the box constraint is - is now priced in. In other words, the traditional no arbitrage linear pricing cannot capture the whole pricing process, in the sense that the value of the security is not the expected discounted value of future cash flows. One has to add the rent associated with physical possession of the security. The tighter is the box constraint at date 0 (the higher is $\mu_{j 0}^{i}$ ), the higher will be the price of the security that serves as collateral in repo.

At the next date, the box constraint is just a no-short-sales restriction whose shadow price enters in the following pricing relation

$$
q_{j s}=\sum_{\xi: t(\xi)=2} \frac{\lambda_{\xi}^{i}}{\lambda_{s}^{i}} p_{\xi} B_{j \xi}+\frac{\mu_{j s}^{i}}{\lambda_{s}^{i}}
$$

\subsubsection{Repo specialness}

Securities in relative scarcity trade on special, that is, below the GC rate. When the repo rate is on special, there is an incentive for the owner of the specific security to lend it in the repo market and borrow funds at a favorable rate to reinvest the cash at a higher rate, for example by borrowing another security and investing at GC rate. Such opportunities are not scalable and are limited by the scarcity of the security available at the date repo agreements are made. ${ }^{25}$

To be more precise, if agents have access to a risk free borrowing and lending, recall that, by an arbitrage argument, pointed out in Duffie [10], the repo rate must be bounded from above by some risk-free interest rate. To simplify exposition we will identify the highest repo rate of an issuer, the general collateral (GC) rate, with the risk free rate $(\mathrm{RF})$. Let $\lambda_{1}^{i}$ be de sum of the multipliers of

\footnotetext{
${ }^{24}$ There is an important difference between the choice variables $x^{i}$ and $y^{i}$. Whereas the former is nonnegative, the latter has no natural lower bound and may take values in the full linear space. Such a linearity combined with monotonicity of preferences are the foundation for standard finance theory: it will no longer apply once we introduce repo.

${ }^{25}$ If instead the repo rate were above the GC rate, then someone who borrows cash at the GC rate can use it to give a cash loan, in exchange to borrowing a security at the repo rate, making an arbitrage gain.
} 
agent $i$ 's budget constraint at all states of date 1, i.e., $\lambda_{1}^{i}=\sum_{s=1}^{S} \lambda_{s}^{i}$. If there were a risk free one-period bond with interest rate $i$ we would have $\left(\lambda_{0}^{i} / \lambda_{1}^{i}\right)=1+i$ for any agent $i$. This allows us to interpret $\left(\lambda_{0}^{i} / \lambda_{1}^{i}\right)-1$ as the RF rate.

We use the first-order conditions to obtain a pricing formula for the repo rate. Taking the derivative with respect to the position $z_{j}$ :

$$
q_{j 0} h_{j}=\sum_{\xi: t(\xi)=1} \frac{\lambda_{\xi}^{i}}{\lambda_{0}^{i}} q_{j 0} h_{j} r_{j}+\frac{\mu_{j 0}^{i}}{\lambda_{0}^{i}}
$$

and, therefore,

$$
R S_{j} \equiv R F-\rho_{j}=\frac{\gamma_{j}^{i}}{h_{j} q_{j 0}}
$$

where $\gamma_{j}^{i} \equiv \mu_{j 0}^{i} / \lambda_{1}^{i}$ (the rent for borrowing the security).

(RS) associates repo specialness with availability of the security in repos. The larger the shadow price of the box constraint at date $0, \mu_{j 0}^{i}$, the more on special becomes the repo rate. This shadow price relates directly to the strength of the borrowing demand of a given security. ${ }^{26}$ The specialness is then the proportion of the value of the security devoted to pay the rent of borrowing the security, given the haircut (this argument also works with no haircut, that is, when $h_{j}=1$ ).

We conclude that for both valuation and repo purposes what is happening is that a shadow price of the box constraint is being added for possession value. In the next subsection we give an example of an equilibrium with specialness.

\subsection{Equilibrium concept}

We are now ready to introduce the equilibrium concept. Consumer $i$ 's problem is to choose a vector $\left(x^{i}, y^{i}, z^{i}\right) \in \mathbb{R}_{+}^{(1+2 S) L} \times \mathbb{R}_{+}^{(1+S) J} \times \mathbb{R}_{+}^{J}$ that maximizes his utility $u^{i}(x)$ subject to his budget and portfolio constraints (BC.Hyp. $\left.\xi\right)_{\xi \in \boldsymbol{\rho}}$, and $(\text { Box. } \xi)_{\xi \in\left\{0,(s)_{s \in \mathbf{S}}\right\}}$ given the prices $(p, q, r)$.

Definition 1: An equilibrium is an allocation of bundles, security trades and repo positions $(x, y, z)$ together with a price vector $(p, q, r)$ such that: (i) $\forall i \in \mathbf{I}$,

\footnotetext{
${ }^{26}$ Observe that with haircut the possession value over the term of the repo (from 0 to 1 ) becomes $\gamma_{j}^{i} / h_{j} q_{j 0}$. This drives the specialness of the security. In fact, $\gamma_{j}^{i}$ is the date 1 shadow cash flow associated with date 0 box that re-establishes the pricing relationship.
} 
$\left(x^{i}, y^{i}, z^{i}\right)$ solves the consumer $i$ 's problem given $(p, q, r)$; (ii) commodity markets clear: $\sum_{i \in \mathbf{I}}\left(x_{\xi}^{i}-\tilde{\omega}_{\xi}^{i}\right)=0$, at all nodes $\xi$; (iii) securities markets clear: $\sum_{i \in \mathbf{I}} y_{\xi}^{i}=0$ for $\xi \in\left\{0,(s)_{s \in \mathbf{S}}\right\}$; and (iv) repo markets clear: $\sum_{i \in \mathbf{I}} z_{j}^{i}=0, \forall j$.

An important consequence of the box is that if either security or repo positions are bounded from below (e.g. short sales constraint), then so is the other one in any allocation satisfying (iii) and (iv) of Definition 1. A lower bound on securities positions implies the existence of a lower bound on repo positions.

There is a natural extension of Radner's [25] result in our framework:

Proposition 1: Under A1 - A2, if short sales are constrained, then an equilibrium exists.

In the Appendix we give a proof of Proposition 1, along the lines of Radner [25]) with the wealth of new ingredients incorporated (new constraints, repo markets). In the presence of a (nominal) riskless asset a Radner equilibrium without short sales constraints for the standard GEI model can be recovered as an equilibrium for the repo model with zero-haircut. In fact, we can make the repo positions mimic the positions in the riskless asset of the Radner equilibrium.

Our next result may seem to be a slight generalization of Proposition 1 as only the value of short sales, not short sales themselves, need to be bounded, but it turns out to give us an interesting insight on how some institutional arrangements guarantee existence of equilibria (as we explore in Section 4).

Remark 2: Under A1 - A2, if the values of short sales and repo are constrained, then an equilibrium exists.

See the Appendix for a proof that uses the fact that security prices have positive lower bounds (by A1).

We conclude this section with an example of an equilibrium with robust specialness. In practice, specialness occurs when the lender of the security does not lend enough, either around year end as they want all security in their possession around account reporting time, or when the demand from the counterparties to borrow and short the security is very high (as in the recent crisis, for example). Let us illustrate this by having the borrower of the security with a positive shadow price for his box constraint, whereas the lender has this constraint non-binding. Such an example can only be found under incomplete markets. 
Complete markets imply an all or nothing behavior for specialness, a zero shadow price of the box for one agent implies zero shadow prices for the boxes of all other agents. In fact, from (z.Hyp.FOC), if agent $k$ has $\mu_{j 0}^{k}=0$, then $r_{j}=$ $\lambda_{0}^{k} / \lambda_{1}^{k}$. So, for $i \neq k$, again by (z.Hyp.FOC), we have $\mu_{j 0}^{i}=\left(\lambda_{0}^{i}-\lambda_{1}^{i} \lambda_{0}^{k} / \lambda_{1}^{k}\right) q_{j 0} h_{j}$, where $\lambda_{0}^{k} / \lambda_{1}^{k}=\lambda_{0}^{i} / \lambda_{1}^{i}$, as markets are complete.

Example of robust specialness: Let us consider a three dates economy with two states of nature at date 1 . Denote the date 1 nodes by 11 and 12 and the date 2 nodes by 21 and 22. There is one good and one security. Markets are incomplete. The security pays one unit of the good in each state of dates 1 and 2 , that is, $B_{\xi}=1, \forall \xi>0$. There are two agents, namely $\mathrm{A}$ and $\mathrm{B}$. Agent $\mathrm{A}$ is the only one who is endowed with the security, with $e_{0}^{A}=0.01$. The haircut in repo is $1 \%$, so $h=0.99$. In the example, the two agents do leverage as in the repo collateral multiplier example in Section 2 (so B leverages up his repo position up to $1=0.01 /(1-h))$. Then, B sells back to A the shaved portion at the end of the looping (still at date 0$){ }^{27}$

Preferences are of the form $u^{i}(x)=\sum_{\xi} \alpha_{\xi}^{i} \ln x_{\xi}^{i}$. Set $\left(\alpha_{0}^{A}, \alpha_{11}^{A}, \alpha_{12}^{A}, \alpha_{21}^{A}, \alpha_{22}^{A}\right)=$ $(1.8,2,1,0.04,1)$ and $\left(\alpha_{0}^{B}, \alpha_{11}^{B}, \alpha_{12}^{B}, \alpha_{21}^{B}, \alpha_{22}^{B}\right)=(2.5,1,1,1,1)$. The following prices $p_{\xi}=1, \forall \xi,\left(q_{0}, q_{11}, q_{12}\right)=(1,0.04,0.064)$, repo rate $\rho=0.05$ and allocations

\begin{tabular}{|c|c|c|}
\hline & $\left(y_{0}^{i}, y_{11}^{i}, y_{12}^{i}, z^{i}\right)$ & $\left(x_{0}^{i}, x_{11}^{i}, x_{12}^{i}, x_{21}^{i}, x_{22}^{i}\right)$ \\
\hline$i=A$ & $(1,-1,-1,-1)$ & $(1,2,7 / 5,1,21.875)$ \\
\hline$i=B$ & $(-1,1,1,1)$ & $(1,1,1,25,15.625)$ \\
\hline
\end{tabular}

constitute an equilibrium for $\left(\omega_{0}^{A}, \omega_{11}^{A}, \omega_{12}^{A}, \omega_{21}^{A}, \omega_{22}^{A}\right)=(1.01,1.9895,1.3655$, $0.99,21.865)$ and $\left(\omega_{0}^{B}, \omega_{11}^{B}, \omega_{12}^{B}, \omega_{21}^{B}, \omega_{22}^{B}\right)=(0.99,1.0005,1.0245,25,15.625)$.

The box constraint for agent $\mathrm{B}$ is binding with multiplier $\mu_{0}^{B}=0.396$ (agent $\mathrm{B}$ is long in repo). However, the box constraint of agent $\mathrm{A}$ (short in repo) is not binding, so $\mu_{0}^{A}=0$. This equilibrium is specialness robust. Local endowment perturbations will modify the consumption equilibrium allocations but specialness for agent B will still hold.

\footnotetext{
${ }^{27}$ This is apparently in contradiction with our proposal to keep that shaved portion in a segregated account, but is a one-security example where there is no need for that (see footnote 28). But the general approach would also work in this one security case: actually, if we had introduced in the example that segregated account requirement and modified the box constraint accordingly (as in Section 4) the example could be done without having B selling the shaved portion at the end to $\mathrm{A}$ as the modified box of agent $\mathrm{B}$ would be binding.
} 


\section{Equilibrium and the level of re-hypothecation}

If there were just one security, the haircut itself would make the intersection of budget and box constraints a bounded set. ${ }^{28}$ The behavior of the one security case of our two agents example in Section 2 does not directly extend to more securities. To see this, notice that when there are several securities and everybody gets the benefit of haircut posted to them as well as being subject to the inconvenience to post it, the re-hypo rate - the fraction of security borrowings that are lent on or sold - can be one (leverage build-up does not consume liquidity, in the sense of pledging a bigger fraction of agents' assets). The reason is that the security borrowing side is cash generating. Assume that two securities have the same haircut. Then, two agents could combine same value borrowing and lending with successive purchase and sale of the securities (with offsetting values for both repo and security trades). In such an example the haircut of one security is compensated by the other, and haircut alone does not bound potential leverage. This comes from the symmetric treatment of all counterparties compounded with the liberal use of haircut posted by other agents. In the this section we examine the case where the re-hypo rate is directly bounded above, and then we will analyze how the difference between dealers and other agents plays a role. ${ }^{29}$

\subsection{Limited rehypothecation}

When the haircut posted by counterparties (and paid for with their own funds) is set aside, the fraction (re-hypothecation rate) that can be sold or lent of a security never exceeds the haicutted amount that was borrowed. As assets paid for by customers should in general be protected, this is an argument for requiring the haircut to be set aside. We will find bounds for the values of security and repo positions. Let us formalize this.

Definition 2: We call re-hypothecation rate (or re-hypo rate) $H_{j}$ the fraction

\footnotetext{
${ }^{28}$ The argument is as follows. From (Box.0) $\phi_{0}^{i} \geq-z^{i}$, and substituting into (BC.Hyp.0) we get $-q_{0} z^{i}+q_{0} h z^{i} \leq W_{0}^{i} \equiv p_{0} \omega_{0}^{i}+q_{0} e^{i}$. If $z^{i+}=0$, then $z^{i-} \leq W_{0}^{i} /(1-h) q_{0}$. Then, by a feasibility argument, we can bound $z^{k+}$ and then using (BoxH.0) we can bound short sales (and again, by feasibility, also security long positions).

${ }^{29}$ at least far enough along the sequence of repo transactions, as positions become large and, therefore, the mutual exposure of agents very risky.
} 
of the amount of security $j$ that can be sold or lent after being borrowed. We say that agents have limited re-hypothecation if $H_{j} \leq h_{j}<1$.

Aitken and Singh [1] addressed re-hypothecation ${ }^{30}$ in a narrower sense, when collateral posted to a prime broker is again used as collateral by him. Our notion is broader and includes the short sale of that collateral as this collateral security can then be purchased and put in another repo by someone else.

In the example of Section 2 only the shaved amount of security is lent further between the two agents. This means that in such a set-up the effective rehypothecation rate was $h$ (that is, 1 minus the haircut). At each round a fixed portion $(1-h)$ of the security value is not lent further. It is ambiguous with two agents and one security whether the reason is the scarcity of cash or of collateral as in that situation the haircut drives re-hypothecation rate, $H=h$.

Next we show how limited re-hypothecation can be naturally embedded in our repo model. Let us differentiate the borrowing and lending of a security by $z_{j}^{i+}=\max \left\{0, z_{j}^{i}\right\}$ and $z_{j}^{i-}=-\min \left\{0, z_{j}^{i}\right\}$, respectively. Then $z^{i}=z_{j}^{i+}-z_{j}^{i-}$. In the same way we can define $\phi_{j 0}^{i}=\phi_{j 0}^{i+}-\phi_{j 0}^{i-}$. Limited re-hypothecation implies that only a fraction $H_{j}<1$ of security $j$ can be re-hypothecated (available in the box), while $\left(1-H_{j}\right)$ is set aside ${ }^{31}$. Thus, the box constraint becomes

$$
\phi_{j 0}^{i}+H_{j} z_{j}^{i+}-z_{j}^{i-} \geq 0, \forall j \in \mathbf{J}
$$

(BoxH.0) constraint defines a convex set. To see this we just need to rearrange terms as follows: $\phi_{j 0}^{i}+z_{j}-\left(1-H_{j}\right) z_{j}^{+} \geq 0$, where $-z_{j}^{+}$is a concave function.

Lemma 1: Under (BoxH.0) and limited re-hypothecation for every security, the values of security and repo positions are bounded, from above and from below.

Let (BC.Hyp.0): $p_{0} x_{0}^{i}+q_{0}\left(\phi_{0}^{i}+h z^{i}\right) \leq W_{0}^{i}$, where $W_{0}^{i} \equiv p_{0} \omega_{0}^{i}+q_{0} e^{i}$. From (BoxH.0) we have $\phi_{j 0}^{i} \geq z_{j}^{i-}-H_{j} z_{j}^{i+}$, and substituting in (BC.Hyp.0) we have $\sum_{j} q_{j 0}\left(z_{j}^{i-}-H_{j} z_{j}^{i+}+h_{j} z_{j}^{i}\right) \leq W_{0}^{i}$. As $z_{j}^{i}=z_{j}^{i+}-z_{j}^{i-}$, we can write $\sum_{j} q_{j 0}((1-$ $\left.\left.h_{j}\right) z_{j}^{i-}+\left(h_{j}-H_{j}\right) z_{j}^{i+}\right) \leq W_{0}^{i}$. Since $h_{j} \geq H_{j}$, we have that $q_{j 0} z_{j}^{i-} \leq \frac{W_{0}^{i}}{\left(1-h_{j}\right)} \equiv A_{j}^{i}$ holds for any security $j$. By feasibility, this in turn implies that $q_{j 0} z_{j}^{i+}$ is bounded by $\sum_{k \neq i} A_{j}^{k} \equiv \Delta_{j}^{i}$. Now, using (BoxH.0) for security $j$, we have $\phi_{j 0}^{i+}-\phi_{j 0}^{i-} \geq$ $z_{j}^{i-}-H_{j} z_{j}^{i+}$, so $-\phi_{j 0}^{i+}+\phi_{j 0}^{i-} \leq-z_{j}^{i-}+H_{j} z_{j}^{i+}$. Now notice that $\phi_{j 0}^{i+} \phi_{j 0}^{i-}=0$. If

\footnotetext{
${ }^{30}$ Following Lehman Brothers' bankruptcy, Aitken and Singh [1] shows evidence that rehypothecation tends to decline when lenders fear fails by counterparties who are likely to go bankrupt.

${ }^{31}$ possibly in a segregated account.
} 
$\phi_{j 0}^{i+}=0$, then $\phi_{j 0}^{i-} \leq-z_{j}^{i-}+H_{j} z_{j}^{i+} \leq H_{j} z_{j}^{i+}$ and multiplying both sides by $q_{j 0}$ we have $q_{j 0} \phi_{j 0}^{i-} \leq q_{j 0} H_{j} z_{j}^{i+} \leq H_{j} \Delta_{j}^{i}$. Otherwise, if $\phi_{j 0}^{i-}=0$, again by feasibility, knowing from the above argument that counterparties have repo short positions bounded in value, we have $q_{j 0} \phi_{j 0}^{i+} \leq H_{j}(I-1) \max _{i} \Delta_{j}^{i}$.

Once we manage to bound security prices from below, Lemma 1 gives a solution to the well known Hart's [15] counterexample ${ }^{32}$. The obligation to reverse in securities before shorting them (the possession constraint of non-negative "title balance" in the box), in a context where leverage is controlled (like no full re-hypothecation), can reestablish the upper hemi-continuity of the budget correspondence. For the modified box constraint (BoxH.0), Lemma 1 leads us to the following existence result (similarly to what Remark 2 did for the original box (Box.0)).

Theorem 1: Let assumptions A1 and A2 hold. Under limited re-hypothecation for all agents, an equilibrium exists.

Remark 3 (Segregated accounts): The most directly related arrangement consists in requiring that a physical (i.e., in units of the securities) haircut of the collateral is kept by the borrower of securities in a segregated account that is only accessed in the case of a credit event. While this is not the current most common practice, it is a reasonable possible market development that haircuts eventually become segregated because haircuts are paid for with client's money. ${ }^{33}$ In fact we think this can be the explicit object of sensible financial regulation. Of course, $h \geq H$ in this case. Notice that the haircut posted by customers is cash funded by them, so customers could potentially insist on no-rehypothecation of such a portion of their securities that they bought with their own funds. Agents comply to limited re-hypothecation in such a situation.

Let us incorporate more concrete institutional specification showing how bounds occur in the current financial market even without such a regulation.

\footnotetext{
${ }^{32}$ Since then there have been many attempts to resurrect the existence of equilibria. See for example Balasko and Cass [3], Bottazzi [4], [5], Duffie and Shafer [9], Geanakoplos and Polemarchakis [13], and $\mathrm{Ku}$ and Polemarchakis [23].

${ }^{33}$ There are already some rules that head in this direction: a possible reading of some customer protection rules (for example, Rule 15c3-3 of the Securities Exchange Act) is that the broker-dealer should maintain possession of haircuts in repo agreement. See point b4(i) of the Security Lawyers' Deskbook at http://www.law.uc.edu/CCL/34ActRls/rule15c3-3.html, published by University of Cincinnati.
} 


\subsection{Constrained dealers}

The cash benefit associated with security borrowing tends to be only available to counterparties who are known to have their leverage limited (and hence short sale constraints) for regulatory reason or/and business focus (in the case of prime brokers whose business is intermediation). This group of dealers service customers (e.g. bank portfolios, hedge funds, mutual funds and insurance companies) who do not necessarily have such restrictions but have to post haircut when borrowing funds while not getting haircut when they borrow securities. This institutional setting is described by the following assumption

(A3) Non-dealers only engage in repo with dealers. Dealers' security positions are bounded in value, by regulation. Dealers collect haircut but do not pay haircut to non-dealers.

The balance-sheet size limitations of dealers/prime brokers insure compactness of their budget set directly. Their customers' budget sets are also compact because haircut is posted but not received. It is not the fact that such customers face constrained dealers that constrains them directly (customers could face each other through offsetting positions, with the dealers having a small position), but the funding of large positions limits their build up. Let us see how limits imposed on dealers translate into limits for their customers.

The economy for this specific framework is the following. We allow for simultaneous borrowing and lending of the same security by the same agent. ${ }^{34} \mathrm{We}$ refer to $\theta_{j}^{i} \geq 0$ (security borrowing) and $\psi_{j}^{i} \geq 0$ (security lending) as the nonnegative reverse repo and repo positions of agent $i$, respectively. There are two sets of agents: dealers $(\mathbf{D})$ and non-dealers $(\mathbf{N})$.

The exogenous bound on the value of dealers' security positions is given as follows: let $M>0$ be such that, for any security $j$,

$$
\left|q_{j 0} \phi_{j 0}^{i}\right| \leq M, \text { for } i \in \mathbf{D}
$$

Non-dealer's budget constraint at date 0 is

$$
p_{0} x_{0}^{i}+\sum_{j} q_{j 0}\left(\phi_{j 0}^{i}+\theta_{j}^{i}-h_{j} \psi_{j}^{i}\right) \leq p_{0} \omega_{0}^{i}+q_{0} e_{0}^{i}, \quad i \in \mathbf{N} \quad \text { (BC.0.nd) }
$$

\footnotetext{
${ }^{34}$ Observe that when borrowing and lending entered symmetrically in the budget constraint we could write it in terms of the net position but this is no longer the case in this subsection.
} 
Dealer's budget constraint at date 0 is

$$
p_{0} x_{0}^{i}+\sum_{j} q_{j 0}\left(\phi_{j 0}^{i}+h_{j} \theta_{j}^{i}-\psi_{j}^{i}\right) \leq p_{0} \omega_{0}^{i}+q_{0} e_{0}^{i}, \quad i \in \mathbf{D}
$$

It is easy to see that it will never be optimal for non-dealers to engage in simultaneous lending and borrowing of the same security. ${ }^{35}$ Dealers, on the other hand, will want to engage in both sides of the repo market of the same security as this generates liquidity for them: they get the haircut advantage.

The repo rate cannot be the same when dealers are lending and when the dealers are borrowing a certain security $j$. First, if each dealer would be facing just one non-dealer a trivial equilibrium would result. In fact, a dealer would always want extreme positions for both $\theta^{i}$ and $\psi^{i}$, whereas the non-dealer would prefer to have just one of these variables to be positive. Secondly, in general, repo market clearing could not be accomplished as can be seen by aggregating all budget constraints. ${ }^{36}$ Therefore, we allow for two different repo rates: $\rho_{j 2}$ when it is the dealer who lends, and $\rho_{j 1}$ when it is the dealers who borrow (and let $r_{j k}=1+\rho_{j k}$, for $\left.k=1,2\right) .{ }^{37}$ So date 1 budget constraints become the following:

$$
\begin{gathered}
p_{s}\left(x_{s}^{i}-\omega_{s}^{i}\right)+q_{s} y_{s}^{i} \leq p_{s} B_{s}\left(y_{0}^{i}+e_{0}^{i}\right)+\sum_{j \in \mathbf{J}} \pi_{j}\left(r_{j 1} \theta_{j}^{i}-r_{j 2} \psi_{j}^{i}\right), \quad \text { for } i \in \mathbf{D} \\
p_{s}\left(x_{s}^{i}-\omega_{s}^{i}\right)+q_{s} y_{s}^{i} \leq p_{s} B_{s}\left(y_{0}^{i}+e_{0}^{i}\right)+\sum_{j \in \mathbf{J}} \pi_{j}\left(r_{j 2} \theta_{j}^{i}-r_{j 1} \psi_{j}^{i}\right), \quad \text { for } i \in \mathbf{N D}
\end{gathered}
$$

At date 1 the box constraint remains the same and is written as $\phi_{j}^{i}+\theta_{j}^{i}-$ $\psi_{j}^{i} \geq 0$. In the definition of equilibrium we replace condition (iv) by $\sum_{i \in \mathbf{N}} \theta_{j}^{i}=$ $\sum_{i \in \mathbf{D}} \psi_{j}^{i}$ and $\sum_{i \in \mathbf{D}} \theta_{j}^{i}=\sum_{i \in \mathbf{N}} \psi_{j}^{i}$.

Lemma 2: For non-dealers the values of security and repo positions are bounded, from above and from below.

\footnotetext{
${ }^{35}$ In fact, a dealer would always want extreme positions for both $\theta^{i}$ and $\psi^{i}$, whereas the non-dealer would prefer to have just one of these variables to be positive. For example, take $h_{j}=0.9$ and compare $\left(\theta^{i}, \psi^{i}\right)=(0.4,0.2)$ and $\left(\theta^{i}, \psi^{i}\right)=(0.2,0)$. Net positions are the same, but a dealer prefers repo trades $(0.4,0.2)$ while a non-dealer prefers $(0.2,0)$.

${ }^{36} \mathrm{~A}$ common repo rate would guarantee only $\left(\sum_{i \in \mathbf{N}} \theta_{j}^{i}-\sum_{i \in \mathbf{D}} \psi_{j}^{i}\right)+h_{j}\left(\sum_{i \in \mathbf{D}} \theta_{j}^{i}-\right.$ $\left.\sum_{i \in \mathbf{N}} \psi_{j}^{i}\right)=0$.

${ }^{37}$ This does not convert the consumers' problem into the problem considered in Section 3. In fact, such isomorphism required $\frac{1}{r_{j 1}}=\frac{h_{j}}{r_{j 2}}$, but such price relation would lead us to market clearing in a non-allowed way $\left(\sum_{i} \theta_{j}^{i}=\sum_{i} \psi_{j}^{i}\right.$ but we should have $\sum_{i \in \mathbf{N}} \theta_{j}^{i}=\sum_{i \in \mathbf{D}} \psi_{j}^{i}$ and $\left.\sum_{i \in \mathbf{D}} \theta_{j}^{i}=\sum_{i \in \mathbf{N}} \psi_{j}^{i}\right)$.
} 
Lemma 2, shown in the Appendix, leads us to the following result, by adapting the proof of Remark 2 (see also the Appendix):

Theorem 2: If A1-A3 hold, then an equilibrium exists.

\section{Final Remarks}

Our main focus in this paper has been to provide a basis for the theory of the use of securities as collateral and their subsequent re-hypothecation. The box concept and security possession is central in our analysis, and we use it to explore the impact of collateral scarcity in traditional corners of security theory like pricing. As we saw, repo rates may become special due to such scarcity. We do believe that our approach relating possession demand and specialness, can be adapted for currencies, linking currency shortage and funding needs. A dollar shortage becomes the equivalent of the dollar being on special. Also, our modeling of repos departs from the standard GEI model as it becomes the way to properly distinguish issuing from shorting.

The repo collateral multiplier set up a strong base for understanding how leverage is built up through recursive collateral. Many adjacent issues to our subject deserve attention in future work. We discussed some arrangements that bound re-hypothecation, in particular, we saw how regulation imposed on dealers (who have an incentive to build large positions in the model) to limit their leverage gets propagated to the rest of the economy. However, there may be other interesting ones, namely in the context of risk based margining ${ }^{38}$ (which reminds us of the relationship between haircut and volatilities discussed by Geanakoplos [14]), that would have to be explained in detail. Likewise, default (the borrower not returning the money) and fails (the borrower of securities not returning the security) are only hinted at, but have important consequences on re-hypothecation.

\footnotetext{
${ }^{38} \mathrm{~A}$ risk based (var) margin is posted in proportion with the counterparty risk (i.e. the bilateral market risk of the full portfolio of position of a trading customer with his prime broker). It is a form of haircut that does not work security by security but at the bilateral portfolio of trades between two counterparties. This will also limit potential position size as collateral needs to be posted for larger positions.
} 


\section{Appendix}

\section{Proof of Proposition 1:}

1. Security positions are assumed to be bounded from below by $-\tilde{K}_{j}$, for each security $j$. Then at any attainable allocation (satisfying (iii) and (iv) of Definition 1 ), security $j$ positions are bounded from above by $K_{j} \equiv(I-1) \tilde{K}_{j}+\sum_{i} e_{j}^{i}$, and using security $j$ box constraint, (Box. $0_{j}$ ), attainable repo positions are such that $(I-1) K_{j} \geq z_{j}^{i} \geq-K_{j}$. Attainable consumption bundles are bounded by $x_{\xi}^{i} \in\left[0, \sum_{i} \tilde{\omega}_{\xi}^{i}\right]$ at each date-state $\xi$.

The repo rate is actually decided at the initial date, when repos are negotiated. That is, let $R_{j} \equiv \frac{1}{r_{j}}$ be the repo price, for security $j$. Repo prices will be chosen together with $\left(p_{0}, q_{0}\right)$ by an auctioneer, whose payoff function (the value of aggregate excess demand in all date 0 markets) can be made linear in $\left(p_{0}, q_{0}, R\right)$ by making the following change of variables: $\tilde{z}_{j}^{i} \equiv r_{j} q_{j 0} z_{j}^{i}, \forall j$. The modified repo variables are required to satisfy the following (where we will later make $n \rightarrow \infty$ ):

$$
\tilde{z}_{j}^{i} \geq-q_{j 0} K_{j}\left(R_{j}+1 / n\right)^{-1}, \forall j \in \mathbf{J}
$$

We rewrite consumers' budget constraints at dates 0 and 1 and the box constraints at date 0 as follows: ${ }^{39}$

$$
\begin{gathered}
p_{0}\left(x_{0}^{i}-\omega_{0}^{i}\right)+q_{0} y_{0}^{i}+\sum_{j} R_{j} h_{j} \tilde{z}_{j}^{i} \leq 0 \\
p_{s}\left(x_{s}^{i}-\omega_{s}^{i}\right)+q_{s} y_{s}^{i} \leq p_{s} B_{s}\left(y_{0}^{i}+e_{0}^{i}\right)+\sum_{j} h_{j} \tilde{z}_{j}^{i} \\
q_{j 0}\left(y_{j 0}^{i}+e_{j 0}^{i}\right)+R_{j} \tilde{z}_{j}^{i} \geq 0, \forall j \in \mathbf{J}
\end{gathered}
$$

Actually, we will start by relaxing (Box.0) in order to obtain easily the lower semi-continuity of the constraint correspondence of a consumer. That is, we replace (Box.0) by the following (and later we make $n \rightarrow \infty$ ):

$$
q_{j 0}\left(y_{j 0}^{i}+e_{j 0}^{i}\right)+R_{j} \tilde{z}_{j}^{i} \geq-1 / n, \forall j \in \mathbf{J}
$$

2. As usual, we consider a truncated economy where consumption, security and repo individual choices have upper and lower bounds that go beyond the

\footnotetext{
${ }^{39} \mathrm{It}$ is clear from (BC.Hyp.0) and (BC.Hyp.s) that $\tilde{z}_{j}^{i}$ looks like a position in a riskless asset, and therefore, its price $R_{j}$ should be equal to the inverse of 1 plus the risk free interest rate, if (Box.0) were not binding, as argued in our discussion of specialness (see Section 3.2).
} 
attainability bounds by an arbitrary small amount $\varepsilon>0$. Denote by $\mathbf{X} \times \mathbf{Y} \times \tilde{\mathbf{Z}}$ the set of bundles, security and repo positions, respectively, satisfying these bounds. We start by finding a truncated equilibrium where individual choices are optimal in $\mathbf{X} \times \mathbf{Y} \times \tilde{\mathbf{Z}}$, but then we will show that these choices are actually optimal under constraints (BC.Hyp. $\xi$ ) and (Box.0n).

Now, we define a generalized game played by consumers, who maximize utility on $\mathbf{X} \times \mathbf{Y} \times \tilde{\mathbf{Z}}$ subject to the budget constraints and (Box.0n), and the following auctioneers. An initial auctioneer for date 0 chooses $\left(p_{0}, q_{0}, R\right)$ in the simplex in order to maximize

$$
p_{0} \sum_{i \in \mathbf{I}}\left(x_{0}^{i}-\omega_{0}^{i}\right)+q_{0} \sum_{i \in \mathbf{I}} y_{0}^{i}+\sum_{j \in \mathbf{J}} R_{j} h_{j} \sum_{i \in \mathbf{I}} \tilde{z}_{j}^{i}
$$

At date 1 (state $s$ ) there is an auctioneer in each state $s$ who chooses $\left(p_{s}, q_{s}\right)$ in the simplex in order to maximize

$$
p_{s} \sum_{i \in \mathbf{I}}\left(x_{s}^{i}-\omega_{s}^{i}-B_{s} \sum_{i \in \mathbf{I}}\left(y_{0}^{i}+e_{0}^{i}\right)\right)+q_{s} \sum_{i \in \mathbf{I}} y_{s}^{i}-\sum_{j \in \mathbf{J}} h_{j} \sum_{i \in \mathbf{I}} \tilde{z}_{j}^{i}
$$

At the last date, state $s^{+}$, an auctioneer chooses $p_{s^{+}}$in the simplex in order to maximize

$$
p_{s^{+}} \sum_{i \in \mathbf{I}}\left(x_{s^{+}}^{i}-\omega_{s^{+}}^{i}-B_{s^{+}} \sum_{i \in \mathbf{I}}\left(y_{s}^{i}+y_{0}^{i}+e_{0}^{i}\right)\right)
$$

Recall that $r=1+\rho$ and we will see that we can find market clearing repo interest rates $\rho$ that are not extremely negative (i.e., not below -1 ), consistent with the normalization of the price vector $\left(p_{0}, q_{0}, R\right)$ in the simplex.

An equilibrium for this generalized game is a vector $(x, y, \tilde{z}, p, q, R) \in \mathbb{R}_{+}^{I(1+2 S) L}$ $\times \mathbb{R}_{+}^{I(1+S) J} \times \mathbb{R}_{+}^{I J} \times \mathbb{R}_{+}^{(1+2 S) L} \times \mathbb{R}_{+}^{(1+S) J} \times \mathbb{R}_{+}^{J}$, such that, for each player, the respective action solves his optimization problem, constrained by the above bounds on choice variables and parameterized by the other players' actions.

Let us see that the generalized game has an equilibrium since it satisfies all the assumptions in Debreu's (1952, [9]). What needs to be checked is the lower semi-continuity of consumers' constraint correspondence. We show that this follows from the assumption of positive endowments of goods and securities, so that the strict inequality versions of the budget and box constraints have nonempty intersection (which is therefore trivially lower semi-continuous). Now, the constraint correspondence of the consumer is just the closure of this intersection and is also lower-semicontinuous (see Hildenbrand [19, p. 26]). 
First, if $p_{0} \neq 0$ let $\left(x_{0}^{i}, y_{0}^{i}, \tilde{z}^{i}\right)=0, \quad y_{j s}^{i} \in\left(-e_{j 0}^{i}, 0\right), \forall j$, and $\left(x_{s}^{i}, x_{s^{+}}^{i}\right)=0$. Second, if $p_{0}=0$ but $q_{0} \neq 0$, let $y_{j 0}^{i}=-\left(e_{j 0}^{i}-\alpha\right)$, where $\alpha \in\left(0, \min _{k} e_{k 0}^{i}\right)$, $\forall j, \quad\left(x_{0}^{i}, \tilde{z}^{i}\right)=0, y_{j s}^{i} \in(-\alpha, 0), \forall j$, and $\left(x_{s}^{i}, x_{s^{+}}^{i}\right)=0$. Third, if $\left(p_{0}, q_{0}\right)=0$ denoting $\bar{B}_{j s}^{i} \equiv t e_{j 0}^{i}\left(q_{j s}+p_{s} B_{j s}\right)$ where $0<t<1$, let $x_{0}^{i}=0, y_{j 0}^{i}>0, \tilde{z}_{j}^{i}=$ $-\beta R_{j}^{-1} n^{-1}, \forall j$, where $\beta \in\left(0, \min \left\{1, \min _{s} \bar{B}_{j s}^{i} n R_{j} / h_{j}\right\}\right)$. Then, $\left(p_{s} B_{s}+q_{s}\right) e_{0}^{i}+$ $\sum_{j} h_{j} \tilde{z}_{j}^{i} \geq(1-t)\left(p_{s} B_{s}+q_{s}\right) e_{0}^{i} \geq(1-t) \min \left\{\min _{l} B_{s l} e_{0}^{i}, \min _{j} e_{j 0}^{i}\right\}>0$ by A1 and A2. Rewriting (BC.Hyp.s) in terms of gross positions $\left(\phi_{s}^{i}=y_{s}^{i}+y_{0}^{i}+e_{0}^{i}\right)$, we get $p_{s}\left(x_{s}^{i}-\omega_{s}^{i}\right)+q_{s} \phi_{s}^{i}<\left(p_{s} B_{s}+q_{s}\right)\left(y_{0}^{i}+e_{0}^{i}\right)+\sum_{j} h_{j} \tilde{z}_{j}^{i}$ by making $\phi_{j s}^{i} \in\left(0, y_{j 0}^{i}\right), \forall j$, and $x_{s}^{i}=0$; we make $x_{s^{+}}^{i}=0$, as usual. Hence, the interior of the intersection of the budget and box constraints, at all nodes, is non-empty, for any $(p, q, R)$ such that $\left(p_{0}, q_{0}, R\right) \in \Delta^{L+2 J-1},\left(p_{s}, q_{s}\right) \in \Delta^{L+J-1}$ and $p_{s^{+}} \in \Delta^{L-1}$ for every $s$.

3. Moreover, we can show that the equilibrium for the generalized game is an equilibrium for the truncated economy. Let us show that markets clear at date 0 (at later dates market clearing follows by recursive substitution in the respective auctioneers objective functions). The new ingredient in this part of the proof is the clearing in repo markets. The argument is as follows: $\sum_{i \in \mathbf{I}} \tilde{z}^{i} \leq 0$, (otherwise the auctioneer chooses $R_{j}=1$ and Walras' law would not hold), but the excess demand is actually null, as $\sum_{i \in \mathbf{I}} \tilde{z}_{j}^{i}<0$ implied $R_{j}=0$ leading agents' reverse repo toward the upper bound of $\tilde{\mathbf{Z}}_{j}$, so $\sum_{i \in \mathbf{I}} \tilde{z}_{j}^{i}>0$, a contradiction.

4. Actually, $\left(x^{i}, y^{i}, \tilde{z}^{i}\right)$ is an optimal choice for consumer $i$ at prices $(p, q, R)$ for the problem where consumption, security and repo positions are not bounded from above (that is, the only bounds are $y_{j \xi} \geq-\tilde{K}_{j}, \forall \xi$ and $\left(\operatorname{Bound}_{j}\right), \forall j$ ). Suppose it was not, say $\left(\bar{x}^{i}, \bar{y}^{i}, \bar{z}^{i}\right)$ is budget feasible at $(p, q, R)$ and $u^{i}\left(\bar{x}^{i}\right)>$ $u^{i}\left(x^{i}\right)$. A convex combination $\alpha \bar{x}+(1-\alpha) x$, with $\alpha \in(0,1)$, is still strictly better that $x$. When $\alpha$ is small enough, the convex combination lies in $\mathbf{X} \times \mathbf{Y} \times \tilde{\mathbf{Z}}$ and is budget feasible at $(p, q, r)$, a contradiction. We have found an equilibrium for the auxiliary economy parametrized by $n$.

5. Now let $n \rightarrow \infty$. We want to find a cluster point for the sequence $\left(x^{n}, y^{n}, z^{n}, p^{n}, q^{n}, R^{n}\right)$ of equilibria of the auxiliary economies parametrized by $n$. Let us re-normalize prices so that $\left(p_{0}^{n}, q_{0}^{n}\right)$ is in the simplex (this can always be done as commodity prices are non zero along this sequence): let $\left(\hat{p}_{0}^{n}, \hat{q}_{0}^{n}, \hat{R}_{j}^{n}\right)=$ $\left(p_{0}^{n}, q_{0}^{n}, R_{j}^{n}\right) /\left(\sum_{l} p_{l 0}^{n}+\sum_{j} q_{j 0}^{n}\right) .{ }^{40}$ By compactness, $\left(x^{n}, y^{n}, \hat{p}_{0}^{n}, p_{-0}^{n}, \hat{q}_{0}^{n}, q_{-0}^{n}\right)$ has a cluster point. Pass to the respective converging subsequence. We want to show that $R_{j}^{n}$ does not have 0 as a cluster point. The first order condition on $\tilde{z}_{j}^{i}$

\footnotetext{
${ }^{40}$ Notice that $R_{j}^{n} \tilde{z}_{j}^{i n}=q_{j 0}^{n} z_{j}^{i n} \Leftrightarrow \hat{R}_{j}^{n} \tilde{z}_{j}^{i n}=\hat{q}_{j 0}^{n} z_{j}^{i n}$.
} 
requires $\hat{R}_{j}^{n} \geq \sum_{s} \lambda_{s}^{i n} / \lambda_{0}^{i n}$ (recall that $\tilde{z}_{j}^{i}$ is only bounded from below), where $\lambda_{s}^{i n} / \lambda_{0}^{i n}=\frac{D_{1 s} u^{i}\left(x^{i n}\right)}{D_{10} u^{i}\left(x^{i n}\right)} \frac{\hat{p}_{10}^{n}}{p_{1 s}^{n}}$. Now, by A1, $D_{1 s} u^{i}(x) / D_{10} u^{i}(x)$ has a positive minimum on $\left\{x: u^{i}(x) \geq u^{i}\left(\omega^{i}\right)\right.$ and $\left.x \leq \sum_{i} \omega^{i}\right\}$. On the other hand, $\hat{p}_{10}^{n}$ cannot have a zero cluster point. Otherwise, denoting by $E_{10}$ the canonical vector in the direction of this good 1 and by $\phi^{i n}$ the position $y^{i n}+e_{0}^{i}$, the consumption bundle $\left(1-\hat{p}_{10}^{n}\right) x^{i n}+b E_{10}$ would be better than $x^{i n}$ and budget feasible for security and repo positions given by $\left(1-\hat{p}_{10}^{n}\right)\left(\phi^{i n}, \tilde{z}^{i n}\right)$, for $b=\min _{l, j}\left\{\omega_{l 0}^{i}, e_{j 0}^{i}\right\}$, satisfying also (Box.0n) (as $\left.\left|\left(1-\hat{p}_{10}^{n}\right)\left(\hat{q}_{j 0}^{n} \phi_{j 0}^{i n}+\hat{R}_{j}^{n} \tilde{z}_{j}^{i n}\right)\right| \leq\left|\hat{q}_{j 0}^{n} \phi_{j 0}^{i n}+\hat{R}_{j}^{n} \tilde{z}_{j}^{i n}\right|\right)$. So, for any $j, R_{j}^{n}$ does not have 0 as a cluster point, and, therefore, by (Bound), the sequence of repo allocations $\tilde{z}^{n}$ has a cluster point $\tilde{z}$.

6. To find an equilibrium it suffices to show that $\hat{R}_{j}^{n}$ has a cluster point. Notice that market clearing in security and repo markets requires the aggregation of the left hand sides of the $j^{\text {th }}$ box constraints $\left(\right.$ Box. $\left.0 \mathrm{n}_{j}\right)$ to be positive (equal to $\left.\hat{q}_{j 0}^{n} \sum_{i} e_{j 0}^{i}\right)$. Hence, some agent must have a positive left hand side on the

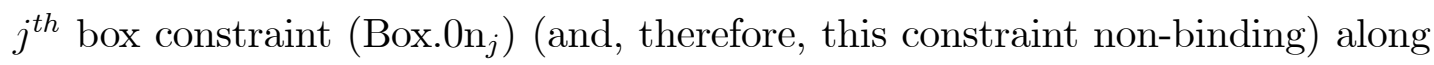
some subsequence. Take the first order condition on $\tilde{z}_{j}$ for this agent. It implies that along this subsequence $\hat{R}_{j}^{n}=\sum_{s} \lambda_{s}^{i n} / \lambda_{0}^{i n}+v_{j}^{i n} /\left(\lambda_{0}^{i n} h_{j}\right)$, where $v_{j}^{i n}$ is the multiplier of the constraint $\left(\right.$ Bound $_{j}$ ) for security $j$. Now, $\lambda_{s}^{i n} / \lambda_{0}^{i n}$ is bounded, as $D_{1 s} u^{i}\left(x^{i n}\right) / D_{10} u^{i}\left(x^{i n}\right)$ and $\hat{p}_{10}^{n} / p_{1 s}^{n}$ are both bounded (by arguments similar to those made in the previous paragraph). We show next that $\left(\right.$ Bound $\left._{j}\right)$ is nonbinding for all $n$ large enough (passing to a subsequence if necessary).

First notice by (Box.0n), for each security $k$, lim inf $\hat{q}_{k 0}^{n} \phi_{k 0}^{i n}+\hat{R}_{k}^{n} \tilde{z}_{k}^{i n} \geq 0$. This together with (BC.Hyp.0) implies that $\hat{q}_{j 0}^{n} \phi_{j 0}^{i n}+\hat{R}_{j}^{n} \tilde{z}_{j}^{i n}$ is bounded from above. Passing to subsequences, if needed, $\hat{q}_{j 0}^{n} \phi_{j 0}^{i n}$ converges and, then, so does $\hat{R}_{j}^{n} \tilde{z}_{j}^{i n}$. Now, $\hat{q}_{j 0}^{n} \nrightarrow 0\left(\right.$ as $\left.\hat{q}_{j 0}^{n} \geq \sum_{s} B_{j s} p_{s}^{n} \lambda_{s}^{i n} / \lambda_{0}^{i n}\right)$ and therefore the sum across agents of the left hand side of $\left(\right.$ Box. $\left.0 \mathrm{n}_{j}\right)$ tends to $\lim \hat{q}_{j 0}^{n} \sum_{i} e_{j 0}^{i}>0$. By the way agent $i$ was chosen, $\lim \hat{R}_{j}^{n} \tilde{z}_{j}^{i n}>-\lim \hat{q}_{j 0}^{n} \phi_{j 0}^{i n} \geq-\lim \hat{q}_{j 0}^{n} K_{j}$. Hence, for $n$ large enough $\left(\right.$ Bound $_{j}$ ) is non-binding.

So $\hat{R}_{j}^{n}$ has a cluster point $\hat{R}_{j}$ and, denoting $\hat{q}_{j 0} \equiv \lim \hat{q}_{j 0}^{n}$, we let $z_{j}^{i}=\tilde{z}_{j}^{i} \hat{R}_{j} \hat{q}_{j 0}^{-1}$. Then $\left(x, y, z, \hat{p}_{0}, p_{-0}, \hat{q}_{0}, q_{-0}, \hat{R}\right)$ is an equilibrium for the original economy. We have proven that if there are short sales constraints an equilibrium exists.

Proof of Remark 2: Consider a sequence of truncated economies whose short sales and security lending are bounded by an increasing bound $\kappa_{j}^{n}$ tending to infinity, even though the values of short sales and repo are constrained. By Proposition 1 , there is an associated sequence of truncated equilibria $\left(\left(x^{n}, y^{n}, z^{n}\right)^{i},\left(\hat{p}_{0}^{n}\right.\right.$, 
$\left.\left.p_{-0}^{n}, \hat{q}_{0}^{n}, q_{-0}^{n}, \hat{r}^{n}\right)\right)$. Recall that along this sequence we have used the normalization $\left(\hat{p}_{0}^{n}, \hat{q}_{0}^{n}\right)$ in the simplex. The first order condition on $y_{j 0}^{n}$ implies that $^{41}$

$$
\hat{q}_{j 0}^{n} \geq \sum_{\xi>0} \frac{D_{1 \xi} u^{1}\left(x^{n}\right)}{D_{x_{10}} u^{1}\left(x^{n}\right)} \hat{p}_{10}^{n} B_{j \xi 1}
$$

As in item 5 in the proof of Proposition 1, assumption A1 guarantees that there are positive lower bounds for both $\hat{p}_{10}^{n}$ and the marginal utilities ratios. The former follows from monotonicity and the interiority of $\left(\omega_{0}^{i}, e_{0}^{i}\right)$ and the latter follows from smoothness. So there exists a uniform positive lower bound for all $\hat{q}_{j 0}^{n}$. Thus we find uniform bounds for $\left(\phi_{j 0}^{i-}\right)^{n}$ and for $\left(z_{j}^{i-}\right)^{n}$. Hence, along the sequence of equilibria the added short sales constraints are non-binding beyond a certain index, at which point we have an equilibrium.

\section{Proof of Theorem 1:}

We will use Lemma 1 and also the fact that security prices are bounded from below (by the same argument as in Remark 2). The proof follows the proof of Proposition 1 with the same initial five items, with (Box.0) replaced by (BoxH. $0_{j}$ ) and replacing $\left(\right.$ Box.0n $\left._{j}\right)$ by the following (denoted (Box.0'n $\left.n_{j}\right): q_{j 0}\left(y_{j 0}^{i}+e_{j 0}^{i}\right)+$ $R_{j}\left(H_{j} \tilde{z}_{j}^{i+}-\tilde{z}_{j}^{i+}\right) \geq-1 / n$. However, item 6 should be redone as follows:

6'. Let us show that $\hat{R}_{j}^{n}$ has a cluster point. Take the first order condition on $\tilde{z}_{j}$ of any agent $i: \hat{R}_{j}^{n}=\sum_{s} \lambda_{s}^{i n} / \lambda_{0}^{i n}+\left(v_{j}^{i n}+\mu_{j 0}^{i n}\right) /\left(\lambda_{0}^{i n} h_{j}\right)$, where $v_{j}^{i n}$ and

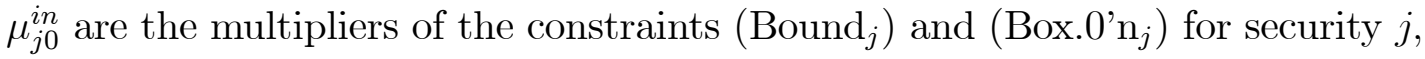
respectively. Now, $\lambda_{s}^{i n} / \lambda_{0}^{i n}$ is bounded, as $\hat{p}_{10}^{n} / p_{1 s}^{n}$ and $D_{1 s} u^{i}\left(x^{i n}\right) / D_{10} u^{i}\left(x^{i n}\right)$ are both bounded (by arguments similar to those made in item 5 ). The ratio $\mu_{j 0}^{i n} / \lambda_{0}^{i n}$ is bounded by the first order condition on $y_{j 0}^{i n}$ (see footnote 41 ). We show next that $\left(\right.$ Bound $\left._{j}\right)$ is non-binding for all $n$ large enough.

By Lemma 1, $\hat{q}_{j 0}^{n} z_{j}^{i n}$ is bounded from above and from below. Now, again by the first order condition on $y_{j 0}^{i n}$, security prices are bounded from below (due to A1), and therefore, repo positions of all agents are bounded from above and from below in the original variables $z_{j}^{i n}$. Recall that $\tilde{z}_{j}^{i n} \equiv \hat{r}_{j}^{n} \hat{q}_{j 0}^{n} z_{j}^{i n}$ (where $\hat{r}_{j}^{n}=1 / \hat{R}_{j}^{n}$ ). As $\hat{R}_{j}^{n} \nrightarrow 0$ we have that $\hat{r}_{j}^{n}$ is bounded and, therefore, $\tilde{z}_{j}^{\text {in }}$ becomes bounded (from above and from below). So, $\left(\right.$ Bound $\left._{j}\right)$ is not binding for $n$ large enough as desired. Then $\hat{R}_{j}^{n}$ has a cluster point, $\hat{R}_{j}$, and, denoting $\hat{q}_{j 0} \equiv \lim \hat{q}_{j 0}^{n}$, we let $z_{j}^{i}=\tilde{z}_{j}^{i} \hat{R}_{j} \hat{q}_{j 0}^{-1}$. Then $\left(x, y, z, \hat{p}_{0}, p_{-0}, \hat{q}_{0}, q_{-0}, \hat{R}\right)$ is an equilibrium.

${ }^{41}$ This first order condition is $q_{j 0}^{n}=\sum_{\xi>0} \frac{\lambda_{\xi}^{i}}{\lambda_{0}^{i}} p_{\xi} B_{j \xi}+\frac{\mu_{j 0}^{i}}{\lambda_{0}^{i}}+\sum_{\xi>0} \frac{\mu_{j \xi}^{i}}{\lambda_{0}^{i}}+\frac{\chi_{j 0}^{i}}{\lambda_{0}^{i}}$, where $\chi_{j 0}^{i}$ is the multiplier of the constraint that bounds security $j$ net trades from below. 
Proof of Lemma 2: This is by assumption for dealers. The box constraint of any agent $i$ is $\phi_{j 0}^{i}+\theta_{j}^{i}-\psi_{j}^{i} \geq 0$, for any security $j$. This implies that $\phi_{j 0}^{i}+\theta_{j}^{i}-$ $h_{j} \psi_{j}^{i} \geq 0$ for any security $j$. Therefore, the budget constraint of a non-dealer, at date 0 , implies that dropping a few terms for any security $j$ and for $i \in \mathbf{N}$ :

$$
q_{j 0}\left(\phi_{j 0}^{i}+\theta_{j}^{i}-h_{j} \psi_{j}^{i}\right) \leq p_{0} \omega_{0}^{i}+q_{0} e_{0}^{i}
$$

(i) Let us start by bounding repo positions. Using inequality (C.1) and the box constraint we get $q_{j 0}\left(\psi_{j}^{i}-\theta_{j}^{i}+\theta_{j}^{i}-h_{j} \psi_{j}^{i}\right) \leq p_{0} \omega_{0}^{i}+q_{0} e_{0}^{i}$. That is,

$$
q_{j 0} \psi_{j}^{i} \leq \frac{p_{0} \omega_{0}^{i}+q_{0} e_{0}^{i}}{\left(1-h_{j}\right)} \equiv L_{j}^{i}
$$

As non-dealers can only engage in repo with dealers, it follows that $q_{j 0} \theta_{j}^{i}$ is bounded by $\sum_{k \in \mathbf{N}} L_{j}^{k}$, for $i \in \mathbf{D}$. Recall that $M>0$ is such that, for any security $j$ and any $k \in \mathbf{D},\left|q_{j 0} \phi_{j 0}^{i}\right| \leq M$. Now, the box constraint of a dealer implies that $M\left(1 / q_{j 0}\right) \geq \psi_{j}^{i}-\theta_{j}^{i}$ and, therefore, $\psi_{j}^{i} \leq M\left(1 / q_{j 0}\right)+\sum_{k \in \mathbf{N}} L_{j}^{k}$. It follows that for $i \in \mathbf{N}, \theta_{j}^{i}$ is bounded by $\left(M\left(1 / q_{j 0}\right)+\sum_{k \in \mathbf{N}} L_{j}^{k}\right)(\# \mathbf{D})$.

(ii) Let us now bound security positions of non-dealers. Using inequality (C.1) we have that, for $i \in \mathbf{N}, q_{j 0}\left(\phi_{j 0}^{i}+h_{j} \theta_{j}^{i}-h_{j} \psi_{j}^{i}+\left(1-h_{j}\right) \theta_{j}^{i}\right) \leq p_{0} \omega_{0}^{i}+q_{0} e_{0}^{i}$. By the box constraint we get $q_{j 0}\left(1-h_{j}\right)\left(\phi_{j 0}^{i}+\theta_{j}^{i}\right) \leq p_{0} \omega_{0}^{i}+q_{0} e_{0}^{i}$. Let $\phi_{j 0}^{i}=\phi_{j 0}^{i+}-\phi_{j 0}^{i-}$, where $\phi_{j 0}^{i+}=\max \left\{0, \phi_{j 0}^{i+}\right\}$ and $\phi_{j 0}^{i-}=-\min \left\{0, \phi_{j 0}^{i}\right\}$. As $\phi_{j 0}^{i+} \phi_{j 0}^{i-}=0$ we obtain

$$
q_{j 0} \phi_{j 0}^{i+} \leq \frac{p_{0} \omega_{0}^{i}+q_{0} e_{0}^{i}}{\left(1-h_{j}\right)}
$$

Now, for $i \in \mathbf{N}, \phi_{j 0}^{i-}$ is also bounded in value as $\sum_{k} \phi_{j 0}^{k+}=\sum_{k} \phi_{j 0}^{k-}+\sum_{k} e_{j 0}^{k}$.

This completes the proof of Lemma 2.

\section{Proof of Theorem 2:}

We adapt the proof of Proposition 1 replacing date 0 budget constraints by (BC.nd) and (BC.d). The box constraint (Box.0) is now replaced by $y_{j 0}^{i}+e_{j 0}^{i}+$ $\theta_{j}^{i}-\psi_{j}^{i} \geq 0$. Let $R_{j k}=1 / r_{j k}, k=1,2$. Then we redo step 1 of the proof of Proposition 1 doing the following change of variables: $\tilde{\theta}_{j}^{i} \equiv r_{j k} q_{j 0} \theta_{j}^{i}(k=1$ if $i \in \mathbf{D}, k=2$ if $i \in \mathbf{N})$ and $\tilde{\psi}_{j}^{i} \equiv r_{j k} q_{j 0} \psi_{j}^{i}(k=1$ if $i \in \mathbf{N}, k=2$ if $i \in \mathbf{D})$.

Constraint $\left(\right.$ Bound $\left._{j}\right)$ is now replaced by: $\psi_{j}^{i} \leq q_{j 0} \bar{K}_{j}\left(R_{j}+1 / n\right)^{-1}$, where $-\bar{K}_{j}$ is a lower bound on repo positions (by Lemma 2 and using the positive lower 
bound on security prices, as in the proof of Remark 2). (BC.Hyp.0), (BC.Hyp.s) and (Box.0n) are easily adapted for the variables $\tilde{\theta}_{j}^{i}$ and $\tilde{\psi}_{j}^{i}$. In item 2 , date 0 auctioneer now chooses $R_{j 1}$ and $R_{j 2}$ to clear the two repo markets of the same security $j$, as explained. Items 3-5 follow as before, and item 6 is redone as in 6' (of proof of Theorem 1) using now Lemma 2 instead of Lemma 1.

\section{Computation to the Example of robust specialness:}

For the proposed portfolio vector and prices, (BC.0) requires $x_{0}^{B}=\omega_{0}^{B}+$ 0.01 and $x_{0}^{A}=\omega_{0}^{A}-0.01$. For $s=1,2$, let $x_{2 s}^{A}=\omega_{2 s}^{A}+e^{A}$ and $x_{2 s}^{B}=\omega_{2 s}^{B}$. Then, $y_{1 s}^{A}=-1$ and $y_{1 s}^{B}=1$. The FOC with respect to $y_{0}^{i}, z^{i}, x_{t}^{i}$ and $y_{1 s}^{i}$ are, respectively,

$$
\begin{gathered}
\lambda_{0}^{i}=\lambda_{11}^{i}+\lambda_{12}^{i}+\lambda_{21}^{i}+\lambda_{22}^{i}+\mu_{0}^{i}+\mu_{11}^{i}+\mu_{12}^{i} \\
\mu_{0}^{i}=h\left(\lambda_{0}^{i}-r\left(\lambda_{11}^{i}+\lambda_{12}^{i}\right)\right) \\
\lambda_{\xi}^{i}=\alpha_{\xi}^{i} / x_{\xi}^{i} \\
\mu_{1 s}^{i}=q_{1 s} \lambda_{1 s}^{i}-\lambda_{2 s}^{i}, s=1,2
\end{gathered}
$$

For $\left(\lambda_{0}^{B}, \lambda_{11}^{B}, \lambda_{12}^{B}\right)=(2.5,1,1),(2 B)$ holds with $\mu_{0}^{B}=0.396$. Using $(4 B)$, we write $(1 B)$ as $2.5=2.396+q_{11}+q_{12}$. Let $q_{11}=0.04$ and $q_{12}=0.064$. Then $(4 B)$ holds for $\left(\mu_{11}^{i}, \mu_{12}^{i}, \lambda_{21}^{B}, \lambda_{22}^{B}\right)=(0,0,0.04,0.064)$. Now (BC.0) and $(3 B, 0)$ hold for $\left(x_{0}^{B}, \omega_{0}^{B}, \alpha_{0}^{B}\right)=(1,0.99,2.5)$, whereas $(\mathrm{BC} .1 \mathrm{~s})$ and $(3 B, 1 \mathrm{~s})$ hold for $\left(x_{11}^{B}, \omega_{11}^{B}, \alpha_{11}^{B}\right)=(1,1.0005,1)$ and $\left(x_{12}^{B}, \omega_{12}^{B}, \alpha_{12}^{B}\right)=(1,1.0245,1)$. Similarly (BC.2s) and $(3 \mathrm{~B}, 2 \mathrm{~s})$ hold for $\left(x_{21}^{B}, \omega_{21}^{B}, \alpha_{21}^{B}\right)=(25,25,1)$ and $\left(x_{22}^{B}, \omega_{22}^{B}, \alpha_{22}^{B}\right)=$ $(15.625,15.625,1)$.

Agent A's box constraints are not binding, so $\mu_{0}^{A}=0, \mu_{11}^{A}=0$ and $\mu_{12}^{A}=0$. Take $(2 A)$, for $\lambda_{11}^{A}=1$ we get $\lambda_{12}^{A}=\lambda_{0}^{A} / r-1$.On the other hand, using $(4 A)$ we write $(1 A)$ as $1.04+1.064 \lambda_{12}^{A}=\lambda_{0}^{A}$. Then $\lambda_{0}^{A}=1.8$ and $\lambda_{12}^{A}=5 / 7$. Choose $\left(x_{0}^{A}, \omega_{0}^{A}, \alpha_{0}^{A}\right)=(1,1.01,1.8),\left(x_{11}^{A}, \omega_{11}^{A}, \alpha_{11}^{A}\right)=(2,1.9895,2)$ and $\left(x_{12}^{A}, \omega_{12}^{A}, \alpha_{12}^{A}\right)=$ $(7 / 5,1.3655,1)$. Now, take $\left(\lambda_{21}^{A}, \lambda_{22}^{A}\right)=(0.04,8 / 175)$ and choose $\left(x_{21}^{A}, \omega_{21}^{A}, \alpha_{21}^{A}\right)=$ $(1,0.99,0.04)$ and $\left(x_{22}^{A}, \omega_{22}^{A}, \alpha_{22}^{A}\right)=(21.875,21.865,1)$.

\section{References}

[1] J. Aitken and M. Singh, "Deleveraging after Lehman - Evidence from Reduced Rehypothecation", IMF Working Paper WP/09/42 (2009). 
[2] A. Araujo, M. Páscoa and J.P. Torres-Martínez, "Collateral Avoids Ponzi Schemes in Incomplete Markets", Econometrica, 70 (2002), 1613-1638.

[3] A. Araujo, J. Fajardo, and M. Páscoa, "Endogenous Collateral", Journal of Mathematical Economics 41 (2005), 439-462.

[4] Y. Balasko and D. Cass, "The Structure of Financial Equilibrium with Exogenous Yields: The Case of Incomplete Markets", Econometrica 57 (1989), $135-62$.

[5] J.-M. Bottazzi, "Incomplete Markets: Transverse Financial Structures", Economic Theory 20 (2002), 67-82.

[6] J.-M. Bottazzi, "Existence of Equilibria with Incomplete Markets: The Case of Smooth Returns", Journal of Mathematical Economics 24 (1995), 59-72.

[7] M. Brunnermeier and L. Pedersen, "Market Liquidity and Funding Liquidity", Review of Financial Studies 22 (2009), 2201-2238.

[8] Debreu, G. "Smooth preferences", Econometrica 40 (1972), 603-615.

[9] Debreu, G. "A social equilibrium existence theorem", Proc. Natl. Acad. Sci. USA 38 (1952), 803-886

[10] D. Duffie, "Special Repo Markets", Journal of Finance 51 (1996), 493-526.

[11] D. Duffie, N. Gârleanu and L. H. Pedersen, "Securities Lending, Shorting, and Pricing", Journal of Financial Economics 66 (2002), 307-339.

[12] D. Duffie and W. Shafer, "Equilibrium with Incomplete Markets, I: A basic model of generic existence", Journal of Mathematical Economics 14 (1985), 285-99.

[13] A. Fostel and J. Geanakoplos, "Leverage Cycles and the Anxious Economy", American Economic Review 98 (2008), 1211-1244.

[14] J. Geanakoplos, "Liquidity, Default, and Crashes: Endogenous Contracts in General Equilibrium", in Advances in Economics and Econometrics: Theory and Applications, Eighth World Conference, Volume II, Econometric Society Monographs 2003, 170-205. 
[15] J. Geanakoplos, "Promises Promises", in The Economy as an Evolving Complex System II, ed. W. Brian Arthur, Steven Durlauf, and David Lane, 1997, 285-320. Reading, MA: Addison-Wesley.

[16] J. Geanakoplos and H.M. Polemarchakis, "Existence, Regularity and Constrained Suboptimality of Competitive Allocations when the Asset Market is Incomplete", in Heller et al., editors, Uncertainty, Information and Communication: Essays in honor of Kenneth J. Arrow, Vol. III. Cambridge, UK: Cambridge University Press, 1986.

[17] J. Geanakoplos and W. Zame, "Default, Collateral and Crashes", Unpublished (1998).

[18] O. Hart, "On the Optimality of Equilibrium when the Market Structure is Incomplete", Journal of Economic Theory 11 (1975), 418-443.

[19] W. Hildenbrand, "Core and Equilibria of a Large Economy", Princeton Univ. Press, Princeton, New Jersey, 1974.

[20] R. Jarrow, "Heterogeneous Expectations, Restrictions on Short Sales and Equilibrium Asset Prices", Journal of Finance 35 (1980), 1105-1113.

[21] C. M. Jones and O. A. Lamont, "Short Sales Constraints and Stock Returns", NBER Working Paper Series 8494, (2001).

[22] B. D. Jordan and S. D. Jordan, "Special Repo Rates: An Empirical Analysis", Journal of Finance 52 (1997), 2051-2072.

[23] B. Ku and H. Polemarchakis, "Options and Equilibrium," Journal of Mathematical Economics 19 (1990), 107-112.

[24] J. Luque, PhD Dissertation, Universidade Nova de Lisboa, Faculdade de Economia, 2009.

[25] R. Radner, "Existence of Equilibrium Plans, Prices and Price Expectations in a Sequence of Markets", Econometrica 40 (1972), 289,303.

[26] D. Vayanos and P.O. Weill, "A Search-Based Theory of On-The-Run Phenomenon", Journal of Finance 63 (2008), 1351-1389. 